\title{
ESCRITORAS EM EXÍLIO DE LÍNGUA: NOTAS DE UMA CORRESPONDÊNCIA
}

\author{
WRITERS IN LANGUAGE EXILE: NOTES OF A \\ CORRESPONDENCE
}

\author{
Maria Angélica Deângeli* \\ Gabriela Oliveira**
}

\section{RESUMO}

O objetivo deste trabalho é o de investigar o papel da língua francesa na obra Lettres parisiennes: bistoires d'exil (1986), da canadense Nancy Huston e da argelina Leïla Sebbar. Trata-se de analisar em que medida o exílio apresenta-se como condição de escrita para as autoras e, também, de que maneira esse movimento geográfico e cultural dá lugar a um questionamento sobre a língua, o lugar da mulher na sociedade, a oposição centro versus margem. Nesse projeto de correspondência, que durou cerca de três anos, Huston e Sebbar traçam um retrato de si mesmas, abordando temas como o cotidiano, a infância, os amores, a paixão pelos livros, e perscrutam os laços do passado, mais precisamente, as complexas relações que se tecem entre a língua do pai e a língua da mãe, o país natal e a terra do outro, enfim, o próprio e o estrangeiro. São esses rastros, apenas perceptíveis na escrita, que procuramos interrogar em nosso trabalho.

Palavras-chave: exílio; língua francesa; escrita.

\section{ABSTRACT}

The aim of this study is to investigate the role of the French language in the work Lettres parisiennes: bistoires d'exil (1986) by the Canadian writer Nancy Huston and the Algerian writer Leila Sebbar. It examines how exile influences the writing of these authors and also how this geographical and cultural movement gives rise to questions about the role of language, the place of women in society, and the opposition of the center versus the border. In this correspondence project, which lasted about three years, Huston and Sebbar trace pictures of themselves, addressing themes such as daily life, childhood, loves, passion for books, and peer into the bonds of the past, more precisely, the complex relationships that are woven between the parent language and the mother tongue, the native country and the land of the other, and finally, about oneself and the foreigner. These tracks, only evident in their writings, are what we seek to examine.

Keywords: exile; french language; writing.

\footnotetext{
* Universidade Estadual Paulista "Júlio de Mesquita Filho", São José do Rio Preto SP. Brasil. deangeli@ ibilce.unesp.br

** Universidade Estadual Paulista "Júlio de Mesquita Filho", São José do Rio Preto SP. Brasil gabriela oliveira_silva@live.com
} 
Nos primeiros tempos, o exílio era, entre outras coisas, o duro osso de viver longe. Agora é também o de morrer longe.

(Mario Benedetti, 2009)

\section{AS CARTAS PARISIENSES: NOTAS PRELIMINARES}

Se o propósito deste trabalho é interrogar o lugar da língua na escrita de Nancy Huston e de Leïla Sebbar, algumas questões subjacentes a essa dimensão de lugar merecem ser explicitadas, a saber, a própria condição da escrita ou a escrita como condição de dizer o lugar ou de se dizer de um lugar e, de modo mais evidente, a questão que diz respeito ao lugar físico-material de sua manifestação, ou seja, ao mesmo tempo, o entorno (que não deixa de ser um lugar) e o acontecimento da própria escrita. No caso específico deste trabalho, cabe então precisar que o material de nossa análise concerne à correspondência mantida entre as duas escritoras, a qual deu origem ao livro intitulado Lettres parisiennes: bistoires d'exil; o lugar físico desse exílio, como o próprio título da obra sugere, refere-se a Paris.

Nesse espaço-tempo físico-material de escrita e de língua, que é também lugar de exílio e de vida, o que se tece é a história singular de cada escritora, um (auto)retrato da relação que cada uma estabelece com a língua de suas escritas e com as identidades fragmentadas que se narram por meio dessa língua desde sempre habitada pelo fantasma do (in)apropriável.

Esboçamos, então, em nosso trabalho de leitura e de análise, o relato de duas mulheres excêntricas, se entendermos esse deslocamento físico como algo da ordem de uma subjetividade escritural que interroga o centro e as margens, as margens a partir do centro ou o centro das próprias margens ${ }^{1}$; pois não podemos deixar de assinalar que Huston e Sebbar se situam de maneira bastante distinta com relação a esse centro - Paris, França - a partir do qual pretendem falar, mesmo se uma causa comum as move em seu projeto de correspondência.

As cartas parisienses surgiram do desejo de dialogar sobre o exílio vivido pelas autoras. No início do projeto, Nancy Huston tinha dúvidas se o que experimentava era, de fato, o exílio e, por isso, sempre acrescentava o adjetivo imaginário ao seu exílio e real ao de Leïla Sebbar. As duas mulheres se escrevem para falar da infância,

1. Para um aprofundamento referente à problemática do centro e das margens nas literaturas francófonas contemporâneas, ver o trabalho de Carla Carlagé: Un centre dans les marges: l'Amérique à la rescousse de la francophonie? (Nouvelles Études Francophones, 2010). 
de amor, de livros, da terra natal, da língua materna e também paterna, enfim, de várias histórias entrecruzadas no percurso de seus exílios.

As cartas começaram a ser trocadas em 1983, porém, a ideia é mais antiga e, por isso, sua publicação premeditada. Huston e Sebbar se conheceram em 1976 quando trabalhavam na organização do projeto Histoire d'Elles - um jornal organizado por e para mulheres, a maioria imigrantes. Foi desse encontro que surgiram a amizade e a ideia das cartas sobre o exílio, a integração, a maternidade, o lugar das mulheres na sociedade, o questionamento em torno da língua e das relações complexas entre todos esses conceitos. Tais problemáticas já faziam parte da vida de ambas, o que facilitou, de certo modo, o início da amizade e a realização de um projeto comum.

Nancy Huston nasceu em Calgary, cidade anglófona no Canadá, morou nos Estados Unidos e mudou-se para França em 1973, aos 20 anos, para fazer mestrado sob orientação de Roland Barthes. Sua pesquisa, sob o título Dire et interdire: éléments de jurologie, foi publicada em 1980, pela editora Payot. Sua carreira de romancista começou em 1981 com Les variations Goldberg; em 1985, publicou Histoire d'Omaya. Antes disso, em 1979, escreveu seu primeiro ensaio em francês, Jouer au papa et à l'amant, e publicou textos em revistas ligadas ao Movimento das Mulheres, entre os anos de 1970 e 1975. Anos mais tarde, com Playsong (1993), Huston voltou pela primeira vez a escrever na sua língua materna e sobre seu país de nascimento. Como o romance foi recusado pelos editores, ela o reescreveu em francês. A nova versão, Cantique des plaines (1993), fez sucesso, rendendo prêmios e polêmicas para a autora ${ }^{2}$. A partir desse momento, Huston passou a escrever seus romances nas duas línguas e traduziu os antigos, porém, seus artigos e ensaios continuam sendo escritos (quase que) exclusivamente em francês. Dentre suas produções destacamse ainda: os romances, La Virevolte (1994), Instruments des ténèbres (1996), L’Empreinte de l'ange (1998), Dolce agonia (2001) e Lignes de faille (2006); e os ensaios Journal de la création (1990), Tombeau de Romain Gary (1995), Nord perdu, (1999), Limbes / Limbo (2000), e L'Espèce fabulatrice (2008), entre outros.

Já Leilla Sebbar é argelina, filha de pai argelino e mãe francesa, ambos professores, recebeu educação francesa e frequentou escolas cuja única língua era o francês, uma vez que seu país era colônia francesa na época. Sebbar mudou-se para a França, em 1961, aos 20 anos, para estudar Letras em Aix en Provence, depois em Paris, na Sorbonne. Ela centrou suas pesquisas, antes de passar à ficção, na figura do bom negro

2. Após quase quatro anos de trabalho, os dois livros foram lançados em datas próximas, sendo que a versão em francês ganhou o prêmio Gonverneur Général de melhor romance, em Quebec. Tal fato desencadeou grande polêmica no meio literário, pois, para alguns críticos, o livro deveria ter concorrido na categoria tradução e não, romance. Para uma leitura detalhada sobre o assunto, ver o artigo de Christine Klein-Lataud: Les voix parallèles de Nancy Huston (1996). 
na literatura colonial francesa do século XVIII, na educação das meninas e sobretudo na violência da qual estas eram vítimas, graças ao trabalho de reflexão com outras intelectuais durante o Movimento de Libertação das Mulberes. Em 1976, Sebbar dirigiu, com outras mulheres, escritoras, universitárias, filósofas e sociólogas, na revista Les Temps Modernes, fundada por Jean-Paul Sartre e Simone de Beauvoir, um número especial sobre a educação das meninas do século XVIII ao XX intitulado Petites filles en éducation. Também fundou, com mulheres jornalistas, fotógrafas, estudantes, professoras e donas de casa, o jornal Histoires d'Elles, um jornal de mulheres, veículo de comunicação artesanal e independente que procurava se destacar das revistas femininas tradicionais. A aventura durou três anos $(1976,1979,1980)$ e, no mesmo período, colaborou com a revista Sorcières, fundada por Xavière Gauthier. Em 1981, dedicou-se a um trabalho sobre a cultura doméstica das mulheres: Des femmes dans la maison, anatomie de la vie domestique.

Antes de seus primeiros textos de ficção, Sebbar publicou ensaios que combinavam pesquisas de campo e reflexão, dentre os quais se destacam: On tue les petites filles (1978), espécie de relato no qual retrata a violência contra as meninas na França e Le pédopbile et la maman (1980), ensaio em que problematiza o amor sexual dos adultos por crianças. Entre seus vários romances, novelas e ensaios, também merecem atenção: La Seine était rouge (1961); Parle mon fils, parle à ta mère (1984); Le Chinois vert d'Afrique (1984); Les Carnets de Shérazade (1985); Silence des rives (1993), ganhador do prêmio Kateb Yacine; e Je ne parle pas la langue de mon père (2003), romance em que a autora passa a limpo um passado obstinadamente marcado pela falta, como assinala Christiane Achour, em um estudo sobre a autora. Ao falar das inúmeras preocupações que acompanham a escrita de Sebbar, Achour afirma:

A primeira é a obsessão da língua, que é ao mesmo tempo espaço de plenitude e falta. A plenitude, a língua francesa, parece ser apenas o canal da transmissão da falta da língua do pai, o árabe; raramente qualificada de língua francesa, é mais prazerosamente designada como "língua da mãe". Não há verdadeiramente escolha, visto que é a única língua aprendida, imposta, dominada (ACHOUR, 2010, p. 7, grifos originais) ${ }^{3}$.

Contrariamente a Sebbar, Huston fala e escreve (em) suas duas línguas, mas essa dupla habilidade escritural também parece reservar-lhe vários conflitos, os quais vão se revelando pouco a pouco em seus escritos. Assim, de acordo com a autora: "[...] ao final de dez anos de vida no estrangeiro, longe de me tornar

3. La première est l'obsession de la langue qui est à la fois l'espace du plein et du manque. Le plein, la langue française, semble n'être que le canal de transmission du manque de la langue du père, l'arabe, rarement qualifiée de langue française, elle est plus volontiers désignée comme de "langue de la mère ». Il n'y a pas véritablement de choix puisque c'est la seule langue apprise, imposée, maîtrisée. 
'perfeitamente bilíngue', eu me sinto duplamente semi-língue, o que não é muito diferente de analfabeta ..." (HUSTON, SEBBAR, 1986, p. 77) ${ }^{4}$. Ou ainda, [o francês] "nunca será nunca para mim uma segunda mãe, mas sempre uma madrasta" (HUSTON; SEBBAR, 1986, p. 13-14) ${ }^{5}$. E a relação com essa madrasta sempre será perpassada pelo sonho do materno ou pela constatação de que o laço materno foi interrompido, também para sempre, pelo abandono, como ela própria afirma: "[...] eu me exilei porque eu estava triste, e eu estava triste (pelo menos é assim que eu explico, agora, as coisas para mim) porque minha mãe me 'abandonou' quando eu tinha seis anos [...]" (HUSTON; SEBBAR, 1986, p. 116) ${ }^{6}$.

O livro Lettres parisiennes: bistoires d'exil representa, dentro da produção das autoras, uma confirmação do lugar do exílio em suas ficções, romances e novelas, e de seus próprios lugares enquanto escritoras em exílio. A escolha do gênero epistolar está diretamente relacionada com o objetivo da obra. Trata-se de um gênero livre, com poucas formalidades, que faz apelo à oralidade e ao subjetivo. É uma forma de expressar pela escrita a subjetividade, evitando o modelamento imposto por outros gêneros, tanto literários quanto acadêmicos. Sebbar celebra a liberdade de ir e vir da escrita epistolar ao afirmar: "Aquilo de que gosto em uma carta é a absoluta liberdade de escrever, de responder ou não, de retomar ou não tal ou tal ponto da carta recebida, de voltar sobre o que considero mais importante, mesmo que não seja o assunto ..." (HUSTON, SEBBAR, 1986, p. 19)7. E ao final da nona carta, enviada sem esperar a resposta da anterior, reitera:

Aquilo de que gosto nessa troca de cartas: pela primeira vez, parece que, depois de sete anos de fiel companheirismo no trabalho ao lado das mulheres, encontro uma maneira de falar com você, por cartas, sem restrição, apesar da restrição primeira que nós nos impusemos de nos escrever essas cartas parisienses interrompidas pela geografia [...] (HUSTON, SEBBAR, 1986$, p. 53$)^{8}$.

Embora, aparentemente, sem restrição, o trabalho de escrita que se constrói na trama da correspondência é fruto de uma negociação constante, não sem tensões, entre o eu e o outro. De uma carta a outra, trata-se de reelaborar o pensamento

\footnotetext{
4. [...] au bout de dix années de vie à l'étranger, loin d'être devenue " parfaitement bilingue », je me sens doublement mi-lingue, ce qui n'est pas très loin d'analphabète.

5. Il ne sera jamais pour moi une deuxième mère, mais toujours une marâtre.

6. Je me suis exilée parce que j'étais triste, et j'étais triste (du moins est-ce ainsi que je m'explique les choses maintenant) parce que ma mère m'a "abandonnée" quand j'avais six ans..

7. Ce que j'aime dans une lettre, c'est l'absolue liberté d'écrire, de répondre ou non, de reprendre ou pas, tel ou tel point de la lettre reçue, de revenir sur ce qui tient à coeur, même si ce n'est pas le sujet.

8. C'est que j'aime dans cet échange de lettres: pour la première fois, me semble-t-il, depuis ces sept années de fidèle compagnonnage dans le travail du côté des femmes, je trouve une manière de parler avec toi, par lettres, sans contrainte, malgré la contrainte première que nous nous sommes imposée de nous écrire ces lettres parisiennes interrompues dans la géographie [...].
} 
sobre si mesmo a partir da restrição primeira e de uma condição quase absoluta, que a presença do outro nos impõe. Desse ponto de vista, a escrita epistolar conduz a uma reavaliação contínua da subjetividade, a qual só pode ser apreendida nos interstícios temporais da própria correspondência. Persson, no ensaio intitulado L'interstice, le dialogue et la migrance, em que analisa a obra de Huston e Sebbar, constata que:

[...] o interstício é a própria base da prática epistolar, visto que entre uma carta e outra existe um tempo de espera vazio. $\mathrm{O}$ intervalo que separa as cartas raramente excede um mês ou seis semanas [...]. Em certo sentido, o interstício apresenta-se talvez menos como uma estratégia do que como um resultado inevitável quando se opta pelo gênero epistolar, mas o fato de escolher uma reflexão a dois por meio das cartas é, na realidade, uma estratégia conscientemente escolhida para a escritura (auto)biográfica (PERSSON, 2012, p. 52-53) ${ }^{9}$.

É nesse tempo de espera vazio que se consolida a escrita de um eu fragmentado pela percepção do outro, observador atento que não cessa de nos erigir um/em retrato de si mesmo, colocando à prova a própria existência e relegando a um tempo remoto a emergência de um eu supostamente verdadeiro, como assinala Huston: "[...] eu me sinto frequentemente falsa [...]: eu sou uma falsa francesa, uma falsa canadense, uma falsa escritora, uma falsa professora de inglês [...]" (HUSTON, SEBBAR, 1986, p. 101) ${ }^{10}$, porque "no fundo, nosso 'verdadeiro' eu é exatamente aquele, raquítico e ridículo, da infância..., não é?" (HUSTON, SEBBAR, 1986, p. $60)^{11}$

No fundo, para retomar a expressão da autora, o verdadeiro eu nunca será revelado, pois nesse jogo especular que vai do retrato ao autorretrato, do biográfico ao autobiográfico, como sugere Persson, o eu nunca se dá completamente a conhecer; o que se percebem são apenas fragmentos de uma identidade sempre a ser refeita, repensada ou até mesmo contrariada. $\mathrm{O}$ em definitivo da identidade não existe, pois essa inscreve-se na lógica de um devir que, ele próprio, só pode ser concebido no movimento de uma outra lógica, que é a da relação. Nesse contexto, o outro surge frequentemente como objeto de comparação; as imagens identitárias vão se alternando e anunciam a diferença irredutível que separa, Huston de Sebbar, mas que também as une nesse projeto comum de correspondência, na tentativa

9. [...] l'interstice est la base même de la pratique épistolaire, puisqu'il existe entre entre chaque lettre un temps d'attente, un espace vide. L'espace qui sépare les lettres publiées excède rarement un mois ou six semaines [...]. En un sens l'interstice se présente peut-être moins comme une stratégie que comme un résultat inévitable lorsqu'on opte pour le genre épistolaire, mais le fait de choisir une réflexion à deux à travers les lettres est bel et bien une stratégie consciemment sélectionnée pour l'écriture (auto)biographique.

10. [...] je me sens souvent fausse [...] je suis fausse Française, une fausse Canadienne, une fausse écrivaine, une fausse professeur d'anglais. .

11. Car après tout, au fond, notre "vrai" moi est bien celui, rabougri et ridicule, de l'enfance..., n'est-ce pas? 
de delinear esse eu quase não capturável pelo outro. Assim, num determinado momento, Sebbar escreve:

Você é flexível, eu tão sou rígida. Eu me digo sempre que o exílio (ou meu cruzamento - é a mesma coisa para mim -) me enrijeceu, enquanto para você o efeito contrário se produziu, e, hoje eu gosto, em você, disso que me deixava desconfortável quando eu a conhecia menos, dessa maneira que você tem de abordar alguém, não necessariamente próximo, manifestandolhe, pelo gesto do rosto e do corpo e por sua maneira de dizer oi ou tchau, que ele existe $\left(\right.$ HUSTON; SEBBAR, 1986, p. 175) ${ }^{12}$.

Ao que, num gesto de questionamento aparentemente colocado em suspenso, visto que sua observação se encontra entre parênteses, Huston responde:

(Eu não penso ter essa capacidade: na verdade, você só me vê quando está aqui, num tipo de situação bem particular - reunião de mulheres ou, pelo menos, de pessoas íntimas; muitas vezes, quando chego em casa, eu me contorço na cadeira, fico vermelha, gaguejo, fico pasma de tédio ou de raiva) (HUSTON, SEBBAR, 1986, p. 185) ${ }^{13}$.

O que parece ter motivado a escrita das cartas foi o desejo de tentar captar os rastros dessa tessitura identitária sempre atravessada pelo outro, assombrada por seus contornos e deflagrada por um gesto que apela inevitavelmente para o compromisso ético da correspondência. Um compromisso que se quer uma promessa com, uma espécie de commitment ou de prise en charge, para empregarmos os termos de Beyssade e Marandin (2009) ${ }^{14}$, em suma, uma responsabilidade dialógica para com outro que está sempre presente, mas também ausente, no discurso, com quem será preciso definir os termos do acordo ou de desacordo.

O objetivo do projeto, como sugerido pelo subtítulo da obra, é contar histórias pessoais sobre a experiência de exílio. E é exatamente isso que encontramos ao longo das 30 cartas: confissões, relatos, análises, provas da existência longe da terra natal, seguidos do difícil desafio de escrever na língua do outro.

O livro foi publicado em 1986, inicialmente com outro subtítulo: autopsie de l'exil (autópsia do exílio). A mudança de subtítulo, de autopsie para bistoires, parece

12. Tu es souple et je suis si raide. Je me dis toujours que l'exil (ou mon croisement - c'est pareil pour moi-) m'a raidie, alors que pour toi l'effet contraire s'est produit et j'aime aujourd'bui, chez toi, ce qui me mettait mal à l'aise quand je te connaissais moins, cette façon que tu as d'aborder queldu'un, pas nécessairement une personne proche, en lui manifestant par le geste du visage et du corps, et ta manière de dire bonjour ou au revoir qu'il existe.

13. (Je ne pense même pas avoir cette faculté: après tout, tu ne me vois que lorsque tu es là, c'est-à-dire dans un type de situation bien particulier - réunion de femmes ou au moins d'intimes; il m'arrive tout le temps, dans d'autres situations, de me tordre sur ma chaise, de rougir, de balbutier, de me sentir défaillir d'ennui ou trembler d'bostilité rentrée.)

14. Para um estudo sobre as noções de commitment ou de prise en charge numa perspectiva dialógica, ver o trabalho de Claire Beyssade e Jean-Marie Marandin: Commitment: une attitude dialogique (2009). Embora essa não seja a abordagem deste trabalho, empregamos tais termos por considerar que eles simbolizam, de alguma forma, o diálogo empreendido pelas autoras. 
revelar como a relação das autoras com suas vivências na França foi mudando no decorrer do projeto. Fazer uma autópsia do exílio seria uma tentativa de enterrá-lo ou de dissecá-lo, colocá-lo, de certo modo, à prova de uma existência passada, já que ele estaria morto; porém, a reflexão sobre o tema as faz perceber que, para elas, é impossível falar de uma experiência de exílio apenas passada ou já consumada, pois esse exílio as constitui e funciona como condição para suas escritas. Viver em outro país, em outra língua, faz parte da identidade dessas mulheres e é algo que não pode ser extirpado.

Se o subtítulo foi modificado, a primeira parte do título, Lettres parisiennes, manteve-se e anuncia a geografia da produção dessas cartas. As duas autoras moram em Paris e preferem escrever uma para outra a marcar encontros casuais, pois, embora livres, os temas das cartas não são casuais nem superficiais. Pensar na proximidade geográfica das autoras confere um significado particular para o ato de escrever tais cartas, cuja escrita é necessária e premeditada. Seria difícil imaginar, num mundo mediado pelo tecnológico, a forma concreta que ganharia, hoje, a correspondência entre Huston e Sebbar. No entanto, o que podemos afirmar é que o projeto empreendido por ambas nos permite uma leitura do exílio como algo que ultrapassa as fronteiras de sua manifestação física, ou seja, o lugar onde eventualmente se concretizaria, e se desenha como o esboço de um pensamento singular sobre o movimento geográfico, humano e de língua como única possibilidade de escrita. É desse exílio que trataremos a seguir.

\section{A MORADA E A LÍNGUA: NOTAS SOBRE O EXÍLIO}

Pensar a questão da língua e (m) sua relação com o exílio implica voltar-se, como anunciamos acima, para um elemento fundamental dessa trama, a saber, o lugar e, consequentemente, o movimento que faz ou não desse lugar um espaço de morada, pois, se o lugar físico a partir do qual as autoras se escrevem aparece claramente definido nas cartas parisienses - "Nós nos engajamos numa correspondência real, nós duas morávamos em Paris e nós realmente nos escrevemos as cartas, enviadas pelo correio de 1983 a 1985, eu acho, regularmente" (KIAN; SEBBAR, 2004 apud PERSSON, 2012, p. 52) $)^{15}$, a relação que cada uma delas estabelece com esse lugar é mais ou menos incerta e, por vezes, não tão acolhedora. Se por um lado a noção de lugar remete a uma certa ideia de origem e de estabilidade, e no caso da

15. Nous nous sommes engagées dans une correspondance réelle, nous babitions tous les deux Paris et nous nous sommes vraiment écrit des letres, envoyées par la poste de 1983 à 1985, je crois, régulièrement. 
correspondência entre Huston e Sebbar tal lugar-ideia refere-se a Paris (morar em Paris, escrever de Paris, viver em Paris); por outro, ele a desloca, a prolonga, como o afirma Calle-Gruber, para uma zona sem próprio (2001) ou para um espaço em que o próprio é do outro e não o é, pertence sem pertencer, fica à deriva. É essa relação incômoda ou não acomodada com o lugar que faz com que as autoras divirjam sobre seus sentimentos de pertencimento, sobre a condição de estar ou não, de ser ou não de um lugar. Para Huston, estar em Paris é, de alguma forma, sentir-se em casa, na ausência de qualquer outra terra a que ela possa se referir como um lugar de origem.

Às vezes me perguntam se um dia eu não gostaria de "voltar para casa", e quando respondo que não tenho mais outro lugar a não ser Paris, ficam perplexos. Eu tento explicar [...]. Não. Nunca me compreendem. Para um europeu, longe de casa, é inconcebível não sentir "saudade de seu país", mais ainda, não ter um país do qual sentir saudade. Às vezes, eu invejo esse apego à terra, à pátria; eu invejo também os "verdadeiros" exilados, aqueles que dizem amar com paixão seu país de origem [...] (HUSTON; SEBBAR, 1986, p. 22, grifos originais) ${ }^{16}$.

Nesse sentido, o movimento evoca, em Huston - e, em francês, podemos jogar facilmente com as palavras e também dizer chez Huston (em Huston e na casa de Huston) - a morada, o chez soi; uma morada, de fato, ausente, visto que falta o lugar de origem ou que a falta permanece, mas que apesar de tudo se faz morada. Ela não tem um país do qual sentir saudades, ou, para acompanharmos idiomaticamente (e em francês) a confissão de Huston, ela não tem o mal do país (le mal du pays), mas, paradoxalmente, a ausência desse mal lhe causa um grande mal-estar, um sentimento de privação da falta, o vazio do lugar, pois, no fundo, ela inveja aqueles que amam apaixonadamente um (o) lugar chamado país.

No entanto, se, para Huston, Paris pode ser um/o lugar da morada, para Sebbar, a percepção não é a mesma; ela acredita não ter lugar em Paris, nem mesmo poder afirmar com certeza que gosta da cidade em que vive. Ela também sente certo mal (j'ai du mal) em relação ao lugar:

Eu digo para mim mesma, Paris: Paris existe e felizmente. [...]. Hoje, eu sei que eu não viveria em outro lugar a não ser em Paris. Eu sei definitivamente, e já lhe disse quanta dificuldade tenho para deixar essa cidade. Eu o faço por obrigação, no entanto, não posso dizer: "Amo Paris". Eu não estou segura de amar Paris (HUSTON, SEBBAR, 1986, p. 38) ${ }^{17}$.

16. Parfois, l'on me demande si je ne soubaiterais pas un jour "rentrer chez moi" et quand je dis que je n'ai plus d'autre chez moi que Paris, on est éburlué. J'essaie d'expliquer [...]. Non. On ne comprend toujous pas. Pour un Européen, il est inconcevable que l'on ne ressente pas, loin de chez soi, "le mal du pays" et a fortiori que l'on n'ait pas de pays pour lequel le ressentir. J'envie parfois leur attachement à leur province ou à leur patrie; j'envie aussi les "vrais exilés", ceux qui disent aimer passionnément leur pays d'origine [...].

17. Je me dis, Paris: Paris existe et beureusement. [...]. Aujourd'bui je sais que je ne vivrais pas ailleurs qu'à Paris. Je le sais définitivement, et j'ai t'ai déjà dit à quel point j'ai du mal à quitter cette ville. Je le fais sous contrainte, et pourtant je ne peux même pas dire: "J'aime Paris." Je ne suis pas sûre d'aimer Paris. 
O desconforto da morada ou, mais precisamente, a dificuldade em torno do lugar experimentado pelas autoras é um tema recorrente das cartas parisienses. Porém, a falência refletida no desencontro com esse lugar, essa défaillance, como afirmam as próprias autoras, é (re)compensada por um sentimento de acolhida na escrita. A falha original do lugar, que a falta da morada evoca, não é preenchida, mas deslocada para um outro lugar, habitada por uma outra falha, provisória, talvez, a partir da qual elas encontram um espaço para poder se dizer, como constatamos nas palavras de Sebbar:

Quanto a mim, eu não tenho lugar, terra calorosa, acolhedora, e não me sinto de lugar nenhum. [...] O que me resta? Ou ainda, como, onde me situar? E você? Às vezes parece que minha única terra, talvez para você também, é a escrita, a escola, o livro. Lugares nobres e derrisórios [...] uma terra bem abstrata [...]. Eu já lhe disse, mas o que escrevo aqui, escrevo como a ponta extrema e cruel do exílio onde estou, na verdade. [...] O exílio é o mal-entendido [...] (HUSTON; SEBBAR, 1986, p. 131-132, grifos nossos) ${ }^{18}$.

\section{Palavras que vão se confirmar também em Huston:}

O que aconteceu, desde então, entre outras coisas, é que eu aceitei habitar esta "terra" que é a escrita, uma terra que é por definição, para cada um de seus inúmeros habitantes, uma ilha deserta. Se sou feliz no exílio (em todos os sentidos da palavra, metafóricos e literais), é porque ele dá forma concreta a essa solidão que é a condição que mais conta para mim (HUSTON; SEBBAR, 1986, p. 137-138, grigo original) $^{19}$.

Expressão do mal-entendido, experiência extrema e cruel, ou solitária, o exílio é a condição que lhes permite dar forma às suas existências, permanecer (demeurer), à maneira do que permanece em uma morada (demeure), ou mesmo, do que permanece para sempre (à demeure ${ }^{20}$, de algum modo, em algum lugar, ainda

18. Pour moi, je n'ai pas de lieu, de terre amicale bienveillante et je ne me sens de nulle part. [...] Que me reste-t-il? Aussi, comment, où me situer? Et toi? Il me semble parfois que ma seule terre, peut-être aussi pour toi, c'est l'écriture, l'école, le livre. Des lieux à la fois nobles et dérisoires [...] une terre bien abstraite... Je te l'ai déjà dit, mais ce que jeécris, je l'écris comme la pointe extreme et cruelle de l'exil où je suis, en vérité. L'exil, c'est le malentendu...

19. Ce qui s'est passé depuis, entre autres choses, c'est que j'ai accepté d'babiter cette "terre" qu'est l'écriture, une terre qui est par définition, pour chacun de ses nombreux babitants, une île déserte. Si je suis beureuse dans l'exil (dans toutes les acceptions du mot, métaphoriques et litérales), c'est parce qu'il donne une forme concrète à cette solitude qui me tient le plus à coeur.

20. A palavra demeure em francês evoca o sentido de morada, domicílio, assim como o fato de permanecer, a estada, algo que remete a uma certa estabilidade do lugar, mas se refere também a um adiamento, a um prazo estendido, um atraso. Derrida, em sua obra intitulada Demeure (1998), analisa como a questão ligada à demeure atravessa toda a reflexão sobre a língua e faz a seguinte observação: "Palavra de origem latina, de novo, e que, por intermédio do provençal, do espanhol (demorar) ou do italiano (demorare) reconduz ao latim demorari, de e morari, que significa esperar e tardar. Há sempre uma ideia de espera, de contratempo, de atraso, de prazo ou de sursis em demeure como em moratória. [...] Etre en demeure é estar atrasado, e mettre en demeure, na linguagem jurídica, é intimar, exigir que alguém cumpra uma obrigação num prazo requisitado. A extensão à habitação, ao abrigo, à residência, à casa, está, 
que essa permanência não se demore muito. E essas existências, mais ou menos demoradas, mais ou menos permanentes, ganham forma e vida por meio da escrita. A combinação terra-escrita-exílio ou, vista de outro um ângulo, exílio-escritaterra, é a aliança que se estabelece ou o laço que permanece, o tempo todo, nas cartas parisienses. A escrita é a única terra que se deixa habitar no plano dessa correspondência; uma terra bem abstrata, certamente, mas que autoriza se dizer de um lugar), e até se dizer feliz.

Toda a dificuldade para pensar o exílio talvez esteja na crença em poder inscrevê-lo num ponto fixo, numa origem, num lugar outro que não a travessia. No entanto, se esse mal-entendido vai se desfazendo ao longo das cartas parisienses e se o exílio ali se inscreve num gesto de movimento, ele não deixa de evocar o rastro de alguma herança. Sebbar, em vários momentos, fala dos laços herdados de seu duplo exílio parental:

Filha de um pai em exílio na cultura do Outro, do Colonizador, longe de sua família, em ruptura de religião e de costumes, filha de uma mãe em exílio geográfico e cultural - minha mãe deixara, no drama, uma família de agricultores de Dordonha para seguir um árabe num país distante -, herdei, acho, desse duplo exílio parental uma disposição ao exílio; e entendo, por exílio, tanto solidão quanto excentricidade (HUSTON; SEBBAR, 1986, p. 51, grifo original) ${ }^{21}$.

Solitário e excêntrico, o exílio aparece aqui como algo da ordem da transmissão, uma herança a ser partilhada, uma linhagem em ruptura e que, apesar de tudo, deve ser perpetuada:

E quanto a mim, parece que estou perdendo meu território, minha terra, o exílio... O que eu faria fora do exílio, desertando o que me funda desde o primeiro dia de minha vida? Felizmente, graças a uma viagem a Marseille, tenho certeza [...] de que não escaparei à divisão biológica da qual nasci. Nada, eu sei, jamais evitará, nem abolirá a ruptura primeira, essencial: meu pai árabe, minha mãe francesa; meu pai mulçumano, minha mãe cristã ; meu pai cidadão de uma cidade marítima, minha mãe habitante do interior da França.... Eu me apego ao cruzamento, em desequilíbrio constante, por medo da loucura e da negação, se eu estou deste ou daquele

primeiramente, ligada ao tempo concedido para a ocupação de um lugar e conduz, dessa forma, à última morada onde reside a morte" (DERRIDA, 1998, p. 102). Caberia, ainda, desvendar outros enigmas envolvendo a palavra demeure, pois, demeurer, enquanto verbo, além de morar, residir, habitar, tem também, como evocado acima, o sentido de ficar, demorar-se, não ir embora. É interessante notar que a expressão à demeure significa em permanência, de maneira estável, para sempre. Estamos, de fato, no domínio do que, por excelência, deveria permanecer, mas não permanece, deveria habitar, mas não encontra abrigo, ou seja, no exílio da própria língua, para sempre (à demeure) língua sem morada (sans demeure).

21. Fille d'un père en exil dans la culture de l'Autre, du Colonisateur, loin de sa famille, en rupture de religion et de contumes, fille d'une mère en exil géographique et culturel - ma mère avait quitté dans le drame une famille d'agriculteurs de Dordogne pour suivre un Arabe dans un pays lointain -, j'ai hérité, je crois, de ce double exil parental une disposition à l'exil, j'entends là, par exil, à la fois solitude et excentricité. 
lado. Então, eu estou na borda de cada uma dessas bordas... (HUSTON, SEBBAR, 1986, p. $199)^{22}$.

Por meio de uma série de oposições binárias - pai árabe/mãe francesa; pai muçulmano/mãe cristã ; pai citadino/mãe camponesa -, que instauram a divisão no cerne da origem, como ruptura primeira e essencial, Sebbar reforça a ideia de sentirse às margens, sem lugar definido, no limite e no extremo do exílio, pois, para a autora, no fim do exílio, está a morte, a loucura. Ela usa com frequência termos que fazem apelo à intersecção, mas também à divisão, à separação e ao desequilíbrio para referir-se à sua existência. Essa divisão, por vezes desestabilizadora, uma divisão em perigo permanente de unidade (p. 27), de unificação, para a qual não haveria sequer uma palavra certa ou justa, faz parte de sua identidade, é o fundamento de sua escrita e a morada de seu exílio.

Experiência limite, entre a vida e a morte, o exílio coloca em cena a questão da loucura, do desequilíbrio constante, da falha, da margem e do desvio. Ele suspende um ritmo contínuo para estabelecer um modo de vida entre aspas, ao lado de, ou, mais exatamente, do lado de fora, destacado da existência ordinária, interrompido de seu fluxo e do qual é preciso emergir.

Mesmo que para Huston, diferentemente de Sebbar, o exílio se apresente como um ato voluntário, ele não deixa de ser um lugar; (quase) um lugar que não o é - o que seria também uma forma de dizer que ele é um outro lado do lugar, ou simplesmente, um outro lugar - e interroga, de maneira direta, a questão do pertencimento, das origens, pois, no fundo, tudo parece remeter a uma única questão, como afirma a própria autora:

[...] nem meu francês, nem meu inglês são naturais. Mas isso vale para o resto, e o exílio quer dizer isto: durante toda nossa vida, aonde quer que possamos ir na superfície do planeta, até mesmo no lugar onde nascemos, nos pedirão explicações sobre nosso outro lugar e nos farão a seguinte pergunta: De onde você vem? (HUSTON; SEBBAR, 1986, p. 196) 23. $^{23}$.

Se o objetivo das cartas é responder a essa questão fundamental, vasculhar alhures o lugar de suas origens, para as autoras, não há como se dizer ou dizer o

22. Et moi, il me semble que je suis en train de perdre mon territoire, ma terre, l'exil... Que ferais-je bors exil, désertant ce qui me fonde depuis le premier jour de ma vie? Heureusement, grâce à un voyage à Marseille, j'ai la certitude [...] que je n'échapperai pas à la division biologique d’où je suis née. Rien, je le sais, ne préviendra jamais, n'abolira la rupture première, essentielle: mon père arabe, ma mère française, mon père musulman, ma mère chrétienne, mon père citadin d'une ville maritime, ma mère terrienne de l'intérieur de la France... Je me tiens au croisement, en déséquilibre constant, par peur de la folie et du reniement si je suis de ce côté-si ou de ce côté-là. Alors je suis au bord de chacun de ces bords...

23. [...] ni mon français ni mon anglais ne coulent de source. Mais c'est pareil pour tout le reste, et l'exil vent dire cela: toute notre vie, où que nous allions sur la surface de la planète, serait-ce l'endroit où nous sommes nées, on nous demandera des comptes sur notre ailleurs en nous posant la question: "D'où venez-vous?" 
lugar de suas origens fora da escrita. Mas não se trata de uma escrita qualquer; é um dito de outro lugar, talvez um interdito que só a ruptura do exílio permita apreender. Também não há como escapar a essa pergunta ou resistir a essa falha originária, pois ela é constitutiva de sua condição de escritoras, ou seja, é o acontecimento da própria escrita.

Eu me recusava a ver que não é nada derrisório fazer um $\mathrm{x}$, sem razão aparente, sobre nossas origens, nossa língua e nossa família. No entanto, essa correspondência com você me ajudou a desfazer essa bela estrutura de defesa. Somente agora, quase dois anos após nossa decisão de trabalharmos juntas sobre o exílio, começo a vislumbrar o sentido da palavra. Sem dúvida, você tinha entendido antes de mim: o "exílio" é apenas a fantasia que nos permite funcionar, e, sobretudo, escrever [...]. Nosso exílio é uma fantasia. Um fantasma (HUSTON, SEBBAR, 1986, p. 208-209, grifos originais) ${ }^{24}$.

A experiência do exílio, ao mesmo tempo como imaginação e como espectro - e por isso como algo que assombra, incessantemente -, é o que permite pôr em prática o mecanismo da escrita; nas cartas parisienses, há uma equação que pode ser lida da seguinte maneira: exilar-se $=$ escrever $=$ viver.

Essa forma tomada pela existência, que é uma tomada de forma própria da escrita, só se torna possível graças à língua francesa. Assim, toda a reflexão empreendida na correspondência está ligada ao fantasma da língua, à sua dimensão fantasmal e fantasmagórica. Parece tratar-se de um dispositivo que põe em funcionamento a lógica do devir (devenir) e da memória (sonvenir), de algo que se inscreve no futuro do acontecimento, mas já é passado, pressupõe o movimento, mas busca a permanência. No entanto, nas cartas parisienses, para servirmo-nos de uma assertiva de Crépon (2005), "só a língua permanece" (p. 19) ${ }^{25}$, no curso do exílio. Mesmo que essa permanência seja ilusória ou provisória, o exílio é, para as autoras, terra de inspiração, de lirismo e de escrita. É o único lugar que lhes permite se dizerem de algum lugar, ainda que seja no infinitamente pequeno das bordas, no invisível das margens ou fora do centro. Dessa forma, exílio e escrita tornam-

24. Je refusais de voir que ce n'est quand même pas rien de faire une croix, sans raison apparente sur ses origines, sa langue et sa famille. Or cette correspondance avec toi m'a aidée à fracasser cette belle structure de défense. Et c'est seulement maintenant, presque deux ans après notre décision de travailler ensemble sur l'exil, que je commence à entr'apercevoir le sens du mot. Sans doute l'avais-tu compris avant moi: l' "exil" n'est que le fantasme qui nous permet de fonctionner, et notamment d'écrire. [...] Notre exil est un fantasme. Un fantôme.

25. Referimo-nos ao texto de Crépon, Langues sans demeure (2005), em que o autor estabelece um diálogo fecundo com a obra de Derrida e de Kafka para discutir questões como a apropriação das línguas, a naturalização dos laços entre língua e comunidade linguística, os contornos da identidade política, a problemática da língua e do idioma. Todas essas questões são pensadas sob o tema da morada, como mencionamos anteriormente; pois, ao mesmo tempo que só a língua permanece (seule la langue demeure), as línguas, são por definição, segundo o autor, línguas sem morada (langues sans demeure) $[\ldots]$ (p. 50). 
se a manifestação de um mesmo lugar, e a fórmula anteriormente descrita, que confere um sentido intrínseco à relação exílio-escrita, só encontra seu lugar, sem de fato jamais encontrá-lo, na língua francesa. Nesse contexto, o ato de escrever é o gesto que torna possível a existência numa língua que, ao mesmo tempo, protege, constitui território, mas também afasta e separa.

A narrativa da adoção do francês como língua de escrita em Huston e em Sebbar confunde-se com a narrativa de suas histórias familiares; narrativa dos laços rompidos com a mãe, por um lado, e dos afetos silenciados e interditados em relação ao pai, por outro. Para Huston, diante do sentimento de ruptura experimentado pelo abandono da mãe, o francês representa um lugar de proteção, e somente a partir desse lugar lhe é possível tecer uma história sem riscos, sem verdade e sem rigor, como ela própria sugere; pois, fora desse lugar, não há sequer história. Se o abandono materno leva à renúncia de algo que lhe parece essencial, ou seja, à recusa de escrever na língua materna, não devemos ignorar que é desse trauma original, e também originário, que se desenha a trama de seu nascimento para a escrita:

\begin{abstract}
Não aspiro, em outros termos, a ser verdadeiramente naturalizada. O que importa para mim e o que me interessa é o cultural e não o natural. [...]. Viver no estrangeiro me permitiu ter, em relação ao país de origem $e$ ao país de adoção, um pequeno recuo crítico: eu os percebo um e outro como culturas. A mesma coisa vale para a língua: apenas a partir do momento em que nada mais era óbvio - nem o vocabulário, nem a sintaxe, nem sobretudo o estilo - a partir do momento em que estava abolido o falso natural da língua materna, encontrei coisas para dizer. Meu "nascimento para a escrita" está intrinsicamente ligado à língua francesa. Não que eu a ache mais bela nem mais expressiva que a língua inglesa, mas, estrangeira, ela é

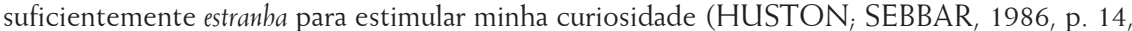
grifos originais) ${ }^{26}$.
\end{abstract}

Para Huston, a desnaturalização da língua materna é a condição desse nascimento para a escrita; é o acontecimento que inaugura o ser no mundo como uma condição do vir-a-ser da língua. E é preciso estranhar a língua, o vocabulário, a sintaxe e principalmente o estilo para poder escrever. Esse estranhamento em relação ao natural - estranhamento que é desvio, mas também intervalo entre o natural e o cultural, o materno e o estrangeiro - é incessantemente buscado por Huston. Para a autora, o afastamento e o desvio quanto às normas, à língua, e até a si mesma, são essenciais para a literatura; a escrita nasceria, assim, desse desejo

26. Je n'aspire pas, en d'autres termes à être vraiment naturalisée. Ce qui m'importe et m'intéresse, c'est le culturel et non le naturel. [...]. Vivre à l'étranger m'a permis d'avoir, vis-à-vis du pays d'origine et du pays d'adoption, un petit recul critique: je les perçois l'un et l'autre comme des cultures. La même chose vaut pour la langue: ce n'est qu'à partir du moment où plus rien n'allait de soi - ni le vocabulaire, ni la syntaxe, ni surtout le style -à partir du moment où était aboli le faux naturel de la langue maternelle, que j'ai trouvé des choses à dire. Ma "venue à l'écriture » est intrinsèquement liée à la langue française. Non pas que je la trouve plus belle ni plus expressive que la langue anglaise, mais, étrangère, elle est suffisamment étrange pour stimuler ma curiosité. 
de tornar estranhos e estrangeiros o conhecido e o familiar e, em seu caso, tal escrita se fundaria ainda sobre um duplo gesto de afastamento, como ela própria constata: "Escrever em francês era, então, um duplo afastamento: primeiro escrever, depois, em francês (ou o contrário: primeiro em francês, depois escrever). Em outras palavras, eu precisava tornar meus pensamentos duas vezes estranhos [...]" (HUSTON; SEBBAR, 1986, p. 212, grifos originais) ${ }^{27}$.

Se, em Sebbar, a narrativa da língua materna pode também ser considerada uma história de distanciamento, ela é, sobretudo, um mal-entendido a ser desfeito, um discurso a ser retificado pela mestiçagem de seu pertencimento. Num gesto que parece contradizer as múltiplas identidades que lhe são atribuídas, Sebbar reivindica, então, o seu lugar de escritora francesa; no entanto, a reivindicação desse dizer é traída pela emergência de um outro lugar, que lhe confere o estatuto de escritora francesa em exílio, subvertendo, assim, o desejo desse lugar (não) encontrado:

Toda vez que eu tenho de falar de mim mesma escrevendo livros, tenho de me situar na minha mestiçagem, repetir que o francês é minha língua materna, explicar porque não sou imigrante, nem árabe, mas simplesmente em exílio [...] de um país que é o país de meu pai e do qual guardo lembranças, vivendo em um país que é o país da minha mãe, da minha língua, do meu trabalho, dos meus filhos, mas onde não encontro verdadeiramente minha terra ... $\left(\right.$ HUSTON; SEBBAR, 1986, p. 133) ${ }^{28}$.

O desencontro com a terra e a falta de identificação com um lugar que possa, de fato, ser o seu país, verdadeiramente sua terra, desencadeiam uma narrativa que oscila entre o sim e o não, entre o pertencer e o não-pertencer, o francês e o árabe, o outro e o mesmo, tal como ela próprio declara Sebbar:

[...] eu não sou imigrante, nem filha da imigração.... Eu não sou uma escritora magrebina de expressão francesa.... Eu não sou uma francesa de origem.... Minha língua materna não é o árabe... [...] eu sou francesa, escritora francesa de mãe francesa e de pai argelino..., e os assuntos de meus livros não são minha identidade, eles são o sinal de minha história de cruzamento, de mestiça obcecada por sua trajetória e pelos caminhos de travessia, obcecada pelo encontro surrealista entre o Outro e o Mesmo, [...] entre a tradição e a modernidade, entre o Oriente e o Ocidente (HUSTON; SEBBAR, 1986, p. 134) ${ }^{29}$.

27. Écrire en français, c'était donc un double éloignement: d'abord écrire, ensuite en français (ou plutôt l'inverse: d'abord en français, ensuite écrire). En d'autres termes, j'avais besoin de rendre mes pensées deux fois étranges..

28. Chaque fois que j'ai à parler de moi écrivant des livres, j'ai à me situer dans mon métissage, à répéter que le français est ma langue maternelle, à expliquer en quoi je ne suis pas imigrée, ni beur, mais simplement en exil [...] d'un pays qui est le pays de mon père et dont j'ai la mémoire, vivant dans un pays qui est le pays de ma mère, de ma langue, de mon travail, de mês enfants mais où je ne trouve pas vraiment ma terre...

29. [...] je ne suis pas immigrée, ni enfant de l'immigration... Je ne suis pas un écrivain magbrébin d'expression française... Je ne suis pas une Française de souche ... Ma langue maternelle n'est pas l'arabe... [...] je suis française, écrivain français de mère française et de père algérien..., et les sujets de mes livres ne sont pas mon identité, ils sont le signe de mon bistoire de croisée, de métisse obsédée par sa route et les chemins de traverse, obsédée par la rencontre surréaliste de l'Autre et du Même, $[. .$.$] de la tradition et de la modernité, de l'Orient et de l'Occident.$ 
Sebbar não é francesa de origem, como assinala em vários momentos de suas cartas, e as histórias de seus livros, sem dúvida, não são sua identidade, mas fazem inevitavelmente parte dela. Nesse interstício identitário, em que para poder afirmar sua condição de ser (francesa, escritora francesa, em exílio) o eu precisa negar o rastro de seus atributos (não ser imigrante, não ser árabe", não ser filha da imigração, não ser escritora magrebina de expressão francesa), há apenas uma certeza: a de que o francês é sua língua materna. No entanto, tal afirmação só parece ganhar força quando contraposta à negação da outra língua, aquela que não é materna, ou seja, $\mathrm{o}$ árabe.

Em Sebbar, a problemática da língua torna-se mais evidente quando se trata de falar da língua não aprendida e com a qual ela mantém laços ambíguos; pois, se o fato de não ter apreendido o árabe aparece como algo explícito pela autora, as razões que perpassam esse acontecimento parecem mais silenciadas:

Pois o que eu sei, depois de tantos anos de múltiplas práticas da língua materna, o francês, é que se eu tivesse aprendido árabe, a língua do meu pai, a língua do autóctone, a falar, ler, escrever nessa língua..., eu não teria escrito. Disso eu tenho certeza hoje. Se eu tivesse ficado no país do meu pai, meu país natal com o qual eu tenho uma história tão ambígua, eu não teria escrito, porque fazer essa escolha significava fazer uma aliança com uma terra, com uma língua, e se fazemos uma aliança ficamos tão perto que não conseguimos mais ver, nem ouvir, nem escrever, não estamos em posição de escrever (HUSTON; SEBBAR, 1986, p. 19) ${ }^{30}$.

Embora o francês seja a língua materna e, não por acaso, para Sebbar, a língua da mãe, é o árabe que faz eclodir a complexidade das relações com as outras línguas, com o país natal e também, não por acaso, com o pai. Se a palavra sebbar significa, em árabe, paciente, como revela a autora ao longo de sua correspondência í o silêncio desse pai paciente, na expressão de sua perseverança, mas também no rastro de seu sofrimento, que se faz presente na escrita de Sebbar. Diretor de escola primária em uma Argélia dominada pela França, seu pai teria conhecido a forte dor de se exilar no próprio país natal, em sua casa, chez soi. Esse exílio doloroso, involuntário e silenciado, instituindo a ruptura no cerne do próprio (ruptura com uma língua, o árabe; com um país, a Argélia, e com uma história pessoal marcada pela presença do outro, o colonizador), tal exílio é determinante da aliança de Sebbar com a escrita. Em árabe, ela não teria escrito; se tivesse ficado na Argélia, também não o teria feito, se estivesse perto (do pai), não escreveria. No entanto, na ausência

30. Car ce que je sais, après tant d'années de pratiques multiples de la langue maternelle, le français, c'est que si j'avais su l'arabe, la langue de mon père, la langue de l'indigène, la parler, la lire, l'écrire..., je n'aurais pas écrit. De cela je suis sûre aujourd'bui. Si j'étais restée dans le pays de mon père, mon pays natal avec lequel j'ai une bistoire si ambiguë, je n'aurais pas écrit, parce que faire ce choix-là, c'était faire corps avec une terre, une langue, et si on fait corps, on est si près qu'on n'a plus de regard ni d'oreille et on n'écrit pas, on n'est pas en position d'écrire. 
de todas essas alianças, na falta de um corpo para encarnar a língua paterna, pois, como ela própria assinala, fazer uma aliança é fazer corpo (faire corps) com uma língua e com uma terra, enfim, na privação de muitos vínculos é que ela escreve. Trata-se de um verdadeiro trabalho de escavação, que dá lugar a uma escrita sobre o vazio, a falha e o fragmento, e busca desenterrar as marcas de uma história esquecida ou silenciada, de uma terra pobre, inculta e estéril em que para fazer brotar a memória, uma outra memória que não tenha sido apagada, é preciso, como diz Sebbar, escavar fundo e longe. A metáfora da escavação concretiza-se no trabalho de desvelo para com a letra; é como se fosse preciso explorar essa terra infértil com as ferramentas de uma outra língua, torná-la fecunda graças ao amor da língua da mãe e não a deixar secar diante do medo. Esse é o tom confessional que também apreendemos nas cartas parisienses:

Eu temo a morte de meu pai. Temo um secamento, porque, hoje, entendo que ele é minha fonte e meu recurso na língua francesa, que teria permanecido letra morta, simples ferramenta de expressão, de comunicação, sem a história paterna, sem a aventura cruzada, amorosa de meu pai e de minha mãe, da Argélia e da França ligadas na ocupação, na guerra, no trabalho de colonização e de libertação (HUSTON; SEBBAR, 1986, p. 161, grifos nossos) ${ }^{31}$.

Sem o pai e o interdito lançado sobre a língua do pai, Sebbar não teria escrito em francês, como ela própria confessa. A ausência da mãe e a distância que se criou entre mãe e filha, entre a filha e a língua da mãe, foram determinantes para o nascimento de Huston para a escrita em língua francesa. De letra morta ou desconhecida, o francês torna-se letra viva e pulsante por meio da qual a narrativa sobre o exílio ganha forma e vida, e as histórias se tecem como uma ficção a fim de cicatrizar a ferida e a diminuir a distância entre as duas margens. No caso de Huston e Sebbar, talvez coubesse sempre ler as duas margens como um infinitamente plural, várias margens, num exercício que combina real e ficção, ficção e autobiografia, ensaio e escrita epistolar, na tentativa de dizer a trama e o trauma do exílio.

\section{UMA OUTRA NOTA: AO MODO DE CONCLUSÃO}

Se as cartas parisienses tratam da questão do exílio geográfico, linguístico e cultural vivido por Huston e Sebbar, importa também para as autoras, nessa correspondência, evocar uma outra forma de exílio na qual acreditam estar

31. J'ai peur de la mort de mon père. J'ai peur d'un tarissement, parce que je comprends aujourd'bui qu'il est ma source et ma ressource dans la langue française qui serait restée lettre morte, simple outil d'expression, de communication, sans l'bistoire paternelle, sans l'aventure croisée, amoureuse de mon père et de ma mère, de l'Algérie et de la France liées dans l'occupations, la guerre, le travail de colonisation et de libération 
engajadas: o exílio relacionado à condição feminina, ou seja, ao fato de ser mulher. É nessa perspectiva que podemos ler o fragmento da oitava carta, de Sebbar para Huston: "Porque eu gostaria que falássemos também desses outros exílios nos quais nos encontramos, enquanto durar a história das mulheres [...] e de repente, começo a falar sobre nossos exílios femininos" (HUSTON; SEBBAR, 1986, p. 40) ${ }^{32}$.

Huston e Sebbar, como mencionamos anteriormente, se conheceram por ocasião do projeto em comum no jornal Histoire d'Elles; o engajamento nas causas femininas, a participação no Movimento de Libertação das Mulheres, os escritos para a revista Sorcières, representam os diversos caminhos partilhados por ambas. No entanto, essa militância, como elas próprias designam, era algo ligado ao momento político em que viviam, a efervescência dos anos 1970. Nas cartas, escritas em meados dos anos 1980, percebe-se um recuo crítico com relação às teorias e às crenças feministas vigentes à época. Ao falar de sua entrada no mundo das letras, por exemplo, Huston relembra uma dessas crenças relacionadas à escrita feminina e afirma não ter hesitado em aderir à causa:

[...] foi mais ou menos naquele momento, em 1975, que a teoria e a prática da "escrita feminina", na França, convergiram em torno de uma ideia singular: a de que as mulheres seriam mais inclinadas ao "significante" do que os homens, ou seja, elas seriam mais sensíveis ao som do que ao sentido das palavras e, por isso, jogariam com o sentido pelos efeitos de aliteração, homonímia e onomatopeia. A ideia caiu como uma luva! - para mim, naquele momento preciso, a língua francesa era apenas matéria sonora (HUSTON, SEBBAR, 1986, p. 103, grifos originais $)^{33}$

Se a festa do significante foi, para Huston, naquele momento preciso, outro acontecimento decisivo ligado à sua entrada na literatura, a fixação pela língua francesa tendo sido o motivo primeiro, como várias vezes assinalou ao longo das cartas; essa adesão à escrita e às causas femininas ganha certo distanciamento no decorrer de seu diálogo com Sebbar e a leva à constatação de que hoje ela não seguiria os mesmos caminhos empreendidos pelas novas profissionais do feminismo. No entanto, se uma certa reserva é expressa com relação às novas formas de engajamento feminista e se o percurso empreendido por Huston e Sebbar conduz a uma direção mais ou menos solitária, nada disso abala os laços tecidos pelas autoras ao lado

32. Parce que j'aimerais qu'on parle aussi de ces autres exils où nous sommes, tant que dure l'bistoire des fermmes. [...] et voilà que je m'engage sur nos exils féminins.

33. [...] c'est vers ce moment-là, en 1975, que la théorie et la pratique de l'"écriture féminine" en France ont convergé autour d'une idée singulière: les femmes seraient davante portées que les bommes sur le "signifiant", c'est-à-dire qu'elles seraient sensibles au son des mots plutôt qu'à leur sens et, du oup, elles joneraient sur le sens par des effets d'allitération, d'bomonymie et d'onomatopée. Je tombais à pic! - moi pour qui la langue française n'était à ce moment précis, que de la matière sonore. 
das mulheres, em nome de outras mulheres, solitárias também, em exílio, às vezes, violentadas, esquecidas, de algum modo, às margens, como Huston e Sebbar.

Logo no início de sua correspondência, Sebbar já anuncia o que se confirmará ao longo das cartas parisienses; trata-se, na verdade, de uma nota referindo-se à sua preocupação com a violência contra as mulheres, as crianças e os árabes. Essa preocupação será, sem dúvida, uma constante de suas escritas assim como uma certa admiração por mulheres excêntricas, rebeldes, exiladas, figuras da excentricidade da História ou na história, tal como assinala Sebbar:

[...] ela prefigurou minha admiração por algumas mulheres da História ou na história. Mulheres excêntricas, rebeldes, guerreiras ou aventureiras, em exílio de seu sexo, de seu meio social, de sua terra natal, de sua religião..., de sua condição de mulher. [...] outras mulheres exploradoras, grandes viajantes, intrépidas e extravagantes que habitaram até à morte outros países que não o país natal... (HUSTON; SEBBAR, 1986, p. 63-64) ${ }^{34}$.

Não se trata, de modo algum, na escrita das autoras de essencializar a condição feminina, de lhe conferir um atributo inerente ao ser mulher; trata-se, antes de tudo, de mostrar que, na complexa trama do exílio, o feminino encontra-se também exilado de si mesmo, de seu corpo, de seu sexo e é, muitas vezes, consumido pela dominação masculina. Segundo uma ótica dicotômica e essencialista da linguagem e do mundo, o masculino determinaria a linhagem, a perpetuação do idêntico, ao passo que o feminino carregaria a marca do diferente, do outro (ou da outra) que não é igual, que se desvia do destino do logos. Nesse sentido, o um da identidade se oporia ao plural da diferença; pois, como nos lembra Cixous (1994), a questão da diferença é uma questão que se coloca para a mulher no âmbito de sua condição.

Uma mulher sente-se como diferente. Quando falamos de diferença sexual em sociedade, ou seja, em guerra, a pessoa que carrega a diferença como um fardo, como uma questão, frequentemente, é a mulher. Uma mulher entra em cena carregando essa diferença estranha que ela só pode descrever nesse espaço diferencial [...]. Onde começa o sentir a diferença? Onde começa nosso sentir a diferença? (CIXOUS, 1994, p. 41) ${ }^{35}$.

Talvez nosso sentir a diferença não possa ainda ser sentido no âmbito do diferente. Talvez ainda a outra ou o outro - e o vocábulo francês l'autre nos priva dessa

34. [...] elle a préfiguré mon admiration pour certaines femmes de l'Histoire ou dans l'bistoire. Des femmes excentriques, en marge, rebelles, guerrières on aventurières, en exil de leur sexe, de leur milieu social, de leur terre natale, de leur religion..., de leur condition de fermme. [...] d'autres femmes exploratrices, grandes voyageuses, intrépides et extravagantes qui ont babite jusqu'à leur mort d'autres pays que le pays natal..

35. Et nous? Une femme se sent comme différente. Quand on parle de différence sexuelle en société, c'est-à-dire en guerre, la personne qui porte la différence comme un fardeau, comme une question, très souvent c'est la femme. Une fermme entre en scène comme ayant cette différence étrange qu'elle ne peut décrire que dans cet espace différentiel toi. Où commence le sentir la différence? Où commence notre sentir la différence? 
diferenciação, pois ele pode remeter tanto ao outro, l'autre l'bomme (o outro homem), quanto à outra, l'autre femme (a outra mulher) - não tenham podido entrar em cena na falta de uma correspondência singular que pudesse acolher sua diferença. Nesse jogo entre outro(s) e outra(s), também como uma forma de sentir-se como diferente, é que podemos perceber o gesto excêntrico encenado pelas cartas parisienses.

\section{REFERÊNCIAS BIBLIOGRÁFICAS}

ACHOUR, C. (2010). Leila Sebbar, le féminisme a l'initiale d'une écriture et son devenir dans l'auvre. Trabalho apresentado no colóquio "Les féministes de la seconde vague en France". Université d'Angers, Maison de la Recherche et Archives du féminisme. Angers, França.

BEYSSADE, C.; MARANDIN, J.-M. (2009). Commitment: une attitude dialogique. Langue française, $\mathrm{n}^{\circ}$ 162, pp. 89-107.

CALLE-GRUBER, M. (2001). La langue des alliances. Mon Algériance. Études littéraires, v. $33, n^{\circ} 3$, pp. 83-94.

CARLAGÉ C. (2010). Un Centre dans les marges: l'Amérique à la rescousse de la francophonie? Nouvelles Études Francophones. v. 25, n 2, pp. 1-15.

CIXOUS, H. (1994). Contes de la différence sexuelle. In: NEGRON, M. et al. (ed.). Lectures de la différence sexuelle. Paris: des femmes/Antoinette Fouquet, pp. 31-68.

CRÉPON, M. (2005). Langues sans demeure. Paris: Galilée.

DERRIDA, J. (1998) Demeure. Paris: Galilée.

HUSTON, N. (2012). Nancy Huston: depoimento [fev. 2012]. Online. Entrevista concedida à revista Psychologies Magazine em 24/02/2012. Disponível em: <http:// www.editions-iconoclaste.fr/spip.php? article1637>. Acesso em: 07 mar. 2016.

HUSTON, N.; SEBBAR, L. (1986). Lettres parisiennes: histoires d'exil. Paris: J’ai lu.

KIAN, S.; SEBBAR, L. (2004). Une entrevue avec Leila Sebbar: L'écriture et l'altérité. The French Review. v. 78, n 1, pp. 128-136.

KLEIN-LATAUD, C. (1996). Les voix parallèles de Nancy Huston. TTR: traduction, terminologie, rédaction. v. $9, \mathrm{n}^{\circ} 1$, pp. 211-231. 
PERSSON, A. (2012). L'interstice, le dialogue et la migrance: Pratiques épistolaires (auto) biographiques dans Lettres parisiennes. Autopsie de l'exil de Nancy Huston et Leilla Sebbar. Nouvelles Études Francophones. v. 27, n 1, Dossier spécial Littérature de la migrance, pp. 51-65.

Recebido: 09/10/2016

Aceito: 02/08/2017 